\title{
AUTOMATIC MEASUREMENT OF ROTATIONAL SPEEDS AND LATHE MAINTENANCE
}

\author{
JURJEVIC, M[arin]; KRSULJA, M[arko]; KATALINIC, B[ranko]; CAR, Z[latan] \& SIKULEC, L[eon]
}

\begin{abstract}
This paper presents a procedure for measuring the rotation velocity of rotating parts. Theoretical introduction defines significant terms such as rotation velocity measurement, angular velocity, angular velocity measurement units and velocity detectors. This paper also reveals a short view on mechanical and electrical tachometers, sensor technology used in tachometers, contact, optic sensors and magnetic sensors. A short view is presented in Lab View user interface created in the laboratory of the Technical Faculty in Rijeka that has been used with stroboscope PCE-OM 15 and with digital tachometer $P C E$ 155. The results are discussed and recommendations given for proper speed measurements and its influences on controlled lathe machine.
\end{abstract}

Keywords: stroboscope, lab view, measurement, speed, maintenance

\section{INTRODUCTION}

Rotation velocity measurement of machine tools is essential because each production system is designed to work with some specific machines that fulfil the task of production, and are designed to operate within the limits of an optimum for a given speed of the machine. In manufacturing system planning and control of process time and its necessary scheduling activities are a common procedure. The results of simulations conducted for big factory systems [1 - 3] depend on the exact speeds and performances of machines included in processing. If a working machine does not work within these limits it leads to a loss in production, in a way that more funds are spent to produce and also the product quality will not be as required because is not processed with sizes that are intended to produce it. Thus, the loss is twofold: on the side of the material that enters the process as material for supply and on the final product, which isn't as planned and will not be able to fulfil its purpose. It is therefore important to know in which regime machine works and whether it is still within the limits of optimality.

This can be achieved in two ways: first way is to work in the machine incorporate measurement of speed detectors that will provide continuous information on the rotation velocity and then the system automatically regulates it, and another method is measuring the external independent measurement instruments, which are obtained only if the information is all still under the required limits and possible correction, then by operator. This paper will show both ways of measuring devices intended for the systematization of this as a different sensor technology used in devices for measuring speed of rotation, a software solutions that help in that, and concrete examples of measuring the rotating velocity of machine tools.

\section{ROTATION VELOCITY MEASUREMENT DEVICES}

Measuring devices for measuring speed of rotation are tachometers (Greek: tachos $=$ speed, metron = measure). According to the principle of measuring tachometers can be mechanical, electrical, magnetic inductive, photoelectric, stroboscopic [2]. The most important parameter to consider is operational tachometer range and accuracy of measurement. Operational area is speed tachometer that can be measured, and the accuracy is typically expressed in unit's $\pm \mathrm{r} / \mathrm{min}(\mathrm{r} / \mathrm{min})$. Sensor technology used in the tachometer can be contact-type photo-electric, inductive and Hall Effect. Due to progress in the design of electronics and sensors, some machinery as the stroboscope remains a simple and reliable backup tool to verify the correct operation of permanently installed sensors $[4,5]$.

Sensor technology used in the tachometers can be contained by the contact probe, magneto sensors, Hall Sensors and magnetic sensors. In the contact-type instrument, probe or sensor tachometric comes into contact with rotating parts. Characteristics of magnetooptical sensors are: light intensity (proportional to input current) and current: DC/AC. Magneto-optical sensor use the principle of Faraday effect where in optical media plain is rotating under the influence of magnetic field.

Magneto-optical sensor is also used as sensors with optical crystal [6 - 9]. They have advantages as: insensitivity to electro-magnetic interference, high insulating capacity, the wide spectral band, lightweight and compact and there is no danger of explosion. Disadvantages are: the relatively high price, special terminal equipment and only for new plants.

\section{LabVIEW}

LabVIEW contains a rich database of ready-made functions for control and management of measurement instruments for data collection and analysis, and data storage. LabVIEW is used in manufacturing a variety of industries, measurements. It is used with various measuring devices (cameras, antennae, thermometers, pressure gauges, moisture meters, pressure gauges, sensors, probes etc.). With these devices collect and handles a large number of statistical data, giving presentations and state diagrams (figure 1). The advantages of virtual instrumentation are: a large choice of different instruments in one place, easy maintenance 
of measuring equipment, flexibility of program modules. Disadvantages of virtual instrumentation are: requires programming experience, acquisition of additional measuring modules increases the price of the initial performance [3].

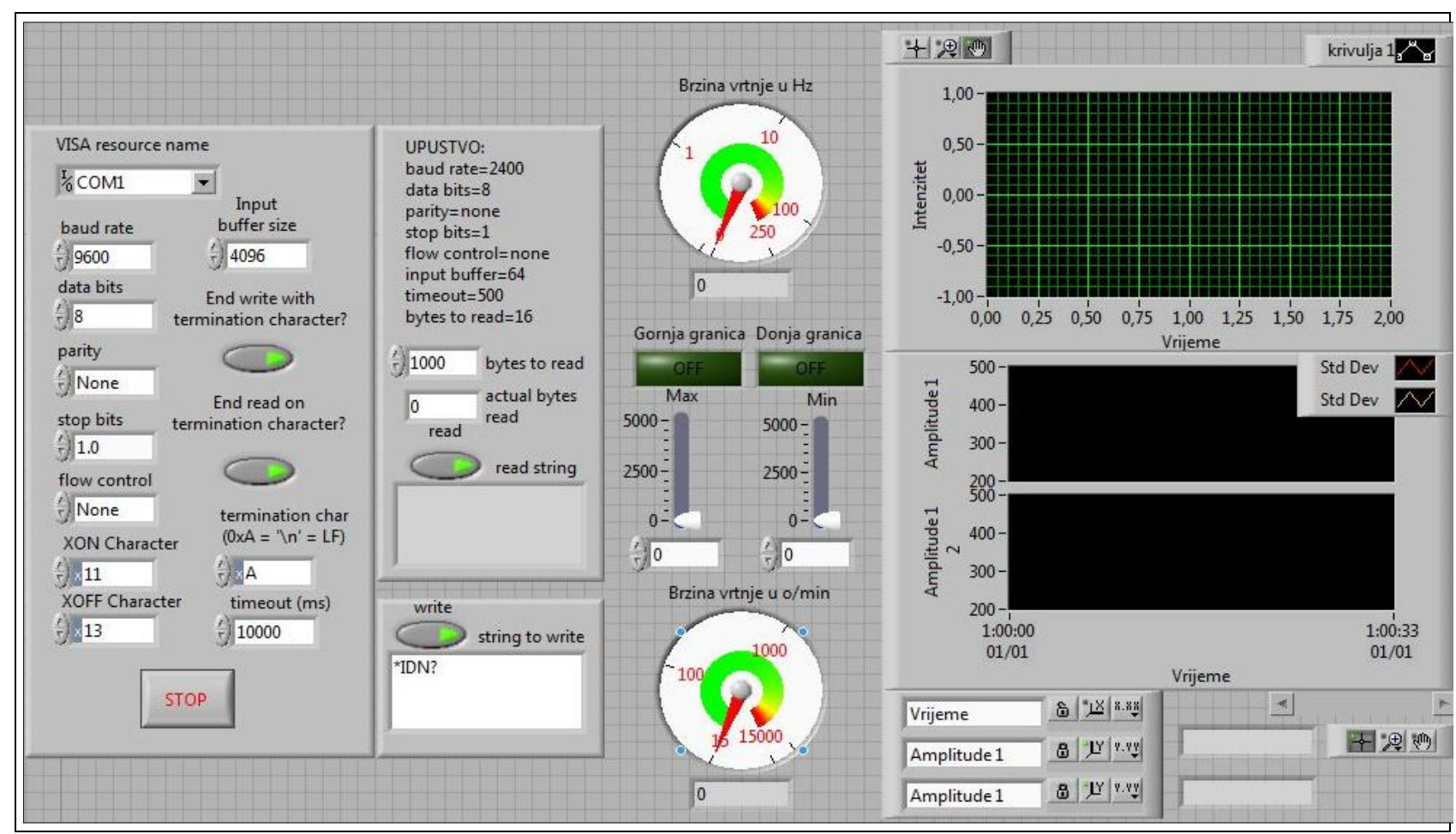

Fig. 1. The user interface in Lab View

\subsection{The appearance of the program created in LabVIEW front panel}

Stroboscope PCE-OM15 was used for measuring the speed of the lathe machine. The interface of Stroboscope is connected with LabVIEW software as shown in figure 1 [3]. On the first side of created software the inlet parameters can be seen for the measuring device that has been used. After reading inlet data sent from device, software is making filtration and convert them into signals which is shown on the second page of the screen where rotation velocity in RPM and $\mathrm{Hz}$ can be read.
In the second page analogue indicators can be seen. It shows min and max rotation velocity which is turning on if speed crosses the limited values. Min and max rotation velocity is setting for each machine individually. On the right side of second page charts in real time shows current rotation velocity. They also show arithmetical mean and standard deviation.

\subsection{Block diagram}

A block diagram designed in LabVIEW software is shown in the picture below.

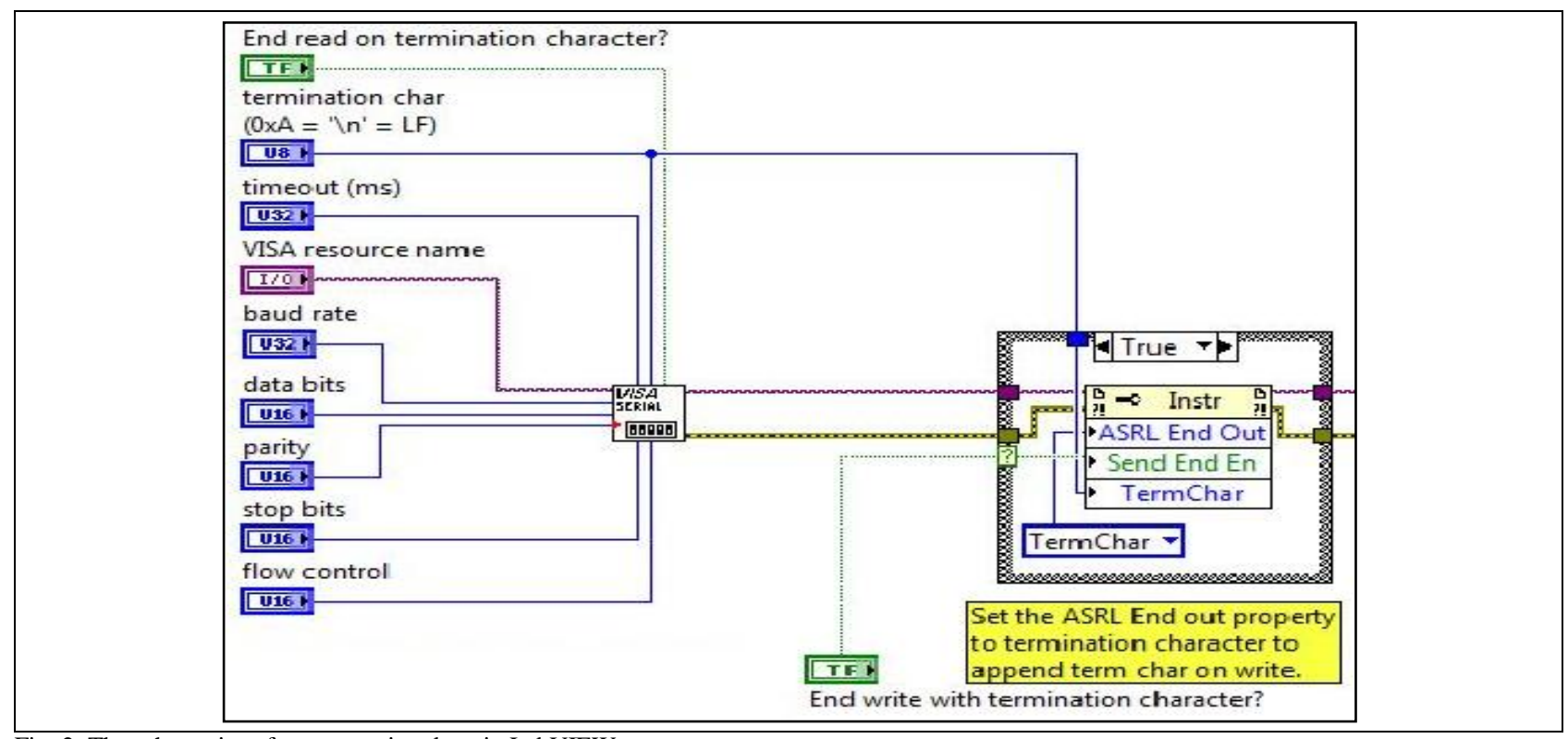

Fig. 2. The schematics of programming done in LabVIEW 
A block diagram (figure 2) represents a code that is executed in the background of the front panel and indicates how the controls and indicators are interrelated eternally. In the end it is possible to form an executable application (Exe). That can be run and on computers that have not installed LabVIEW showing the front panel formed as a standalone application.

\section{ROTATION VELOCITY MEASUREMENTS ANALYSIS OF RESULTS}

Measurements are made with stroboscopes PCEOM15 and PCE 155 (figure 3 and 4) on a lathe machine in Laboratory of Artificially Intelligent Machines and Processing Systems at the Faculty of engineering Rijeka. For these measurements we used stroboscope and computer with software for automatic acquisition of data. Due to progress in the design of electronics and sensors, some machinery (e.g. printing presses and packing machines) can operate without stroboscope assistance, yet the stroboscope remains a simple and reliable backup tool to verify the correct operation of permanently installed sensors [4]. In our case measurements made with the stroboscope illuminate rotational part on which there is an affixed reflective stamp. The stroboscope frequency is changed until the light hits the frequency same as rotating machine part. At this point it seems as if the machine is idle. This is because they are on the same frequency and flash stroboscope shines in the same rhythm in which the head spinning machine and because of the inertia of the human eye seems to be really true. This is the moment when to read the revolution per minute, frequency of the stroboscope because it is an actual rotation velocity of the machine. The program for data acquisition was developed in LabVIEW. The computer serial port is connected to a device for measuring rotation, stroboscope PCE-OM 15.

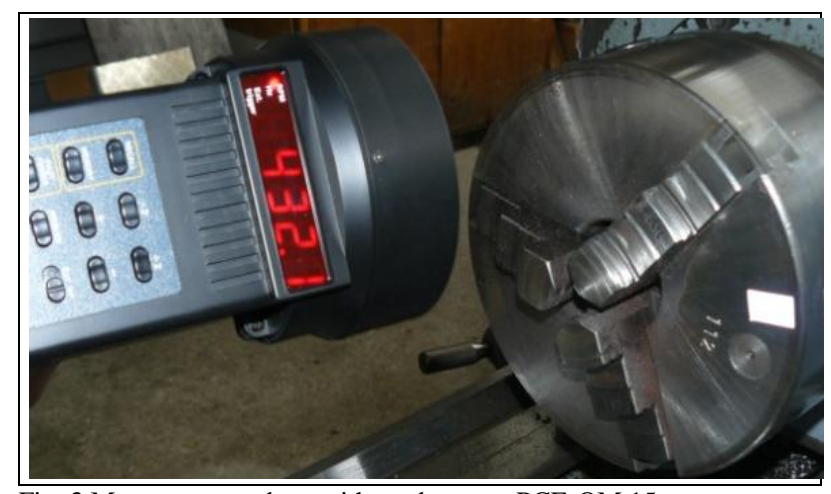

Fig. 3 Measurements done with stroboscope PCE-OM 15

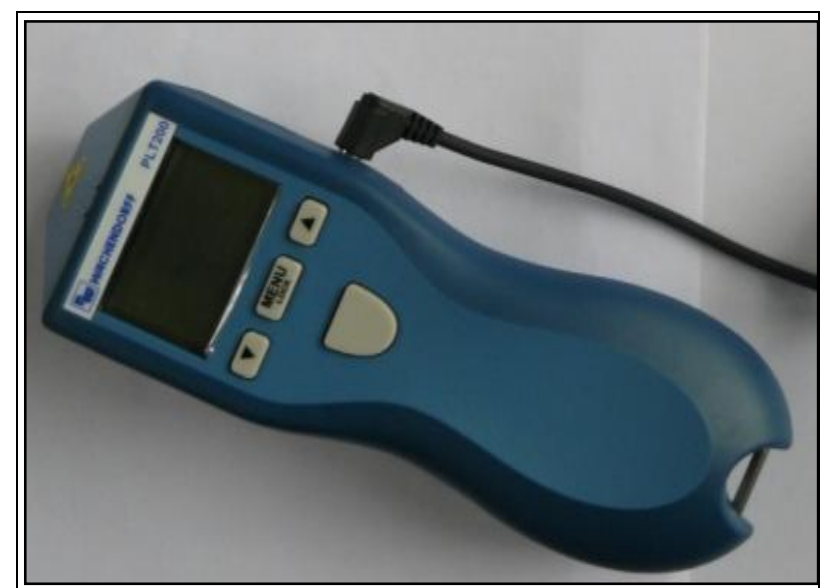

Fig. 4 Additional measurements were done with digital tachometer PCE 155

All input parameters are set in the program in accordance with label instructions and 10 measurements per specified Machine speed setup area are obtained.

Changes manifest through the gears by changing the speed, i.e. increasing or decreasing the speed of rotation relative to the setoff gears in motion. Since it is through these gears that the spindle speed is regulated, a problem arises due to their wear or, in the extreme, breakage. It is therefore important to timely notice of change in the number of revolutions. In case of too large or too small speed comes to increased tool wear, poor quality of the machined surface and the like.

For comparison additional measurements were done with tachometer PCE 155. The software LabVIEW is set for control and acquisition and data storage. The data are stored in excel file, at the figure 5 average measurements of 10 data per machine speed are shown. Analyses of results shown on figure 5 demonstrate that the average deviation from optimum speed is $6.4 \%$. Additionally recommendation is to use this lathe machine at speeds of $1600 \mathrm{r} / \mathrm{min}$ as it has minimum deviation of $3.7 \%$. With factor of $6.5 \%$ we can calculate exact speed used in Tayler equation (1) for optimum tooling wear and total cycle needed for product production and product path trough all operations.

$$
T=C_{T} \cdot v_{C}^{K v}
$$

where $C_{T}$ is Tyler constant and $v_{c} i s$ programmed speed.

\begin{tabular}{|c|c|c|c|c|c|}
\hline Number & $\begin{array}{c}\text { Machine speed } \\
\text { setup r/min }\end{array}$ & Stroboscope r/min & Tachometer r/min & $\begin{array}{c}\text { Average speed } \\
\text { r/min }\end{array}$ & $\begin{array}{c}\text { Average deviation } \\
\%\end{array}$ \\
\hline 1 & 280 & 303.15 & 303 & 303.075 & 7.6 \\
\hline 2 & 400 & 432.1 & 432 & 432.05 & 7.4 \\
\hline 3 & 560 & 588.45 & 603 & 595.725 & 6 \\
\hline 4 & 800 & 850 & 849 & 849.5 & 5.8 \\
\hline 5 & 1120 & 1221 & 1203 & 1212 & 7.6 \\
\hline 6 & 1600 & 1662 & 1662 & 1662 & 3.7 \\
\hline
\end{tabular}

Tab. 1. Additional measurements were done with digital tachometer 


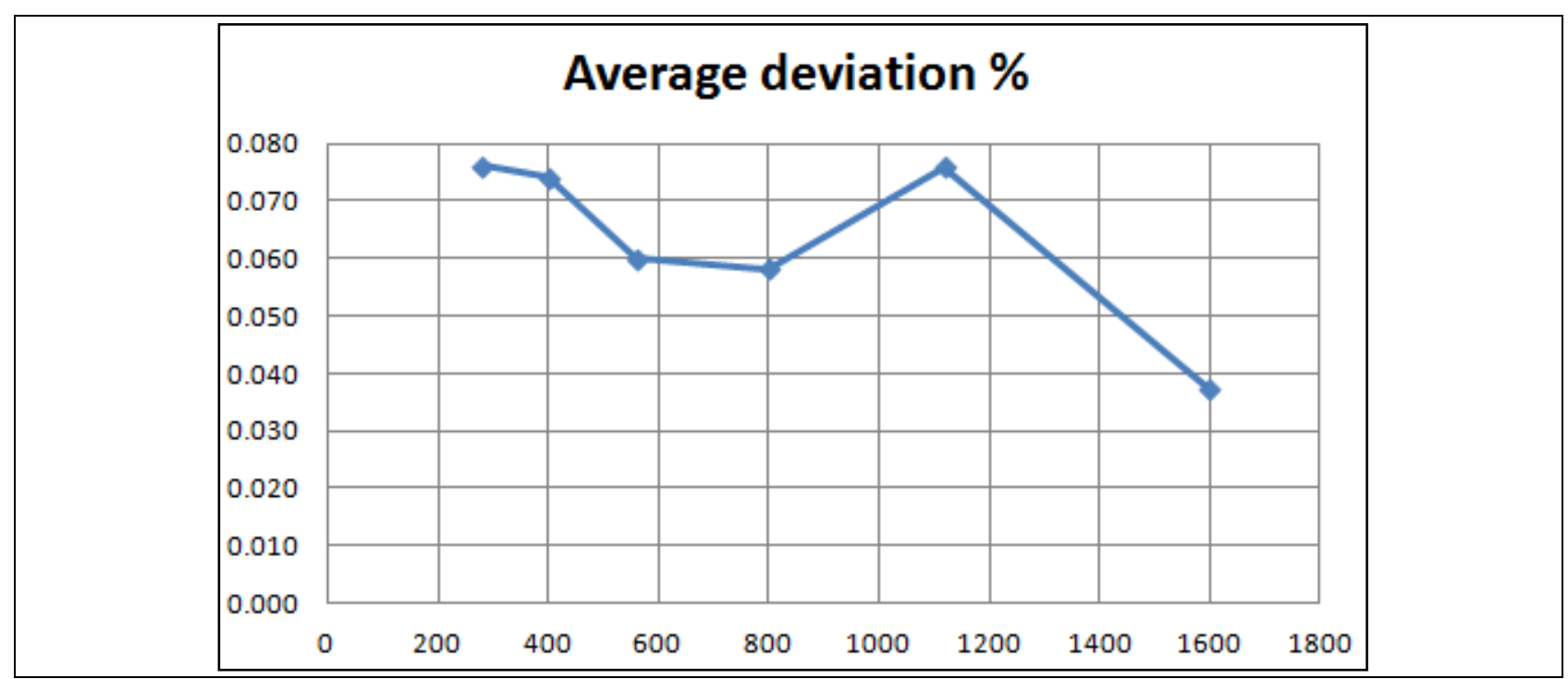

Fig. 5 Additional measurements were done with digital tachometer

\section{CONCLUSION}

Basic terms of rotational velocity have been given, its modes of measurement, various digital ways of measuring the rotation velocity of machine parts. A method for automatic programming of rotational velocity has been given with Lab VIEW software. Measuring devices used for measuring of the rotation velocity are systematized and described and explained. The software for data acquisition is designed in the central part and the way that measuring device communicates with the program and how it can connect other devices is explained in detail. Finally, concrete measurements on machine tools with different machine speed setup have been conducted and data acquisition was performed. The resulting average deviation of $6.4 \%$ of actual setting can be expected. Measurements showed that the lathe machine gears are damaged and should be changed.

The supervision of devices is included in preventive quality assessment and should be conducted in regular intervals. Future investigations will address factory layout and investigation of optimal production path that relays on such quality prevention system. This system will be based on automatic connection of optimisation product path with LabView measurement system cantered on automatic control of machine reliability. Additionally CNC machines with more precise rotation depended on voltage inputs will be controlled.

\section{ACKNOWLEDGEMENTS}

The authors would like to acknowledge the support provided by the National CEEPUS Office of Croatia and National CEEPUS Office Austria, which helped the research through mobility in the frame of the CEEPUS II HR 0108 project.

Also the authors would like to thank Croatian science project number 069-1201787-1754 and the Laboratory of Artificially Intelligent Machines and Processing Systems at the Faculty of Engineering Rijeka.

\section{REFERENCES}

[1] Car, Z., Barišić, B.\& Kršulja, M. (2009). Simulation and Modelling of Paths Processing Time in a Flexible Manufacturing System. Výrobné inžinierstvo, Vol. 3, No. VIII, 2009, pp. 40-45

[2] Kršulja, M.; Cukor, G. \& Car, Z. (2011). Simulation of Product Logistic, Investigation of Facility Layout Capabilities, International Conference on Innovative Technologies IN-TECH, Prague, ISBN: 978-80-904502-6-4, Kudlaček, J.; Car, Z.; Barišić, B.; Pepelnjak, T.; Pakosta, M. \& Kršulja, M. (Ed), pp. 759-761, Tisk AS, s.r.o., Jaroměř

[3] Pašić, M. (2011). Measuring rotation velocity of speeding machines, Bacholer thesis, Department of mechanical engineering, University of Rijeka, Croatia

[4] Vrcan, Željko; Lovrin, Neven; Gregov, Goran. Applications of stroboscopes. Engineering review: Scientific journal of new technology in mechanical engineering, shipbuilding and electrical engineering. 29 (2009), 1; 95-106

[5] http://www.physicstutorials.org/index.php/home/rotationalmotion/angular-velocity, (2012). Online Physics Tutorials, Accessed on: 2012-04-05

[6] http://www.esa.fer.unizg.hr/nastava/meh/_OM/predavanja/OM_pr edavanja\%20BIM.pdf, (2011). Faculty of Electrical Engineering and Computing, University of Zagreb, Croatia, Accessed on: 2012-03-29

[7] http://www.esa.fer.unizg.hr/nastava/meh/_OM/predavanja, (2007). Faculty of Electrical Engineering and Computing, University of Zagreb, Croatia, Accessed on: 2012-04-12

[8] http://www.automation.siemens.com/w1/automation-technologyspeed-sensors, (2012). Siemens, Accessed on: 2012-05-02

[9] http://www.baumer.com/motion/tachogeneratorsresolvers/en.html, (2012) Baumer, Accessed on: 2012-05-16

http://www.ni.com/labview/, (2012). National Instruments Corporation, Accessed on: 2012-05-18 